(C) 2022, The Authors. Published by Elsevier Inc. and Fass Inc. on behalf of the American Dairy Science Association ${ }^{\circledR}$. This is an open access article under the CC BY license (http://creativecommons.org/licenses/by/4.0/).

\title{
Hay provision affects 24-h performance of normal and abnormal oral behaviors in individually housed dairy calves
}

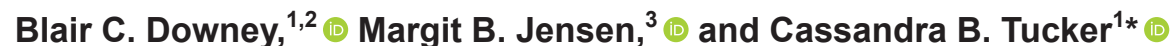 \\ ${ }^{1}$ Center for Animal Welfare, Department of Animal Science, University of California, Davis 95616 \\ ${ }^{2}$ Animal Behavior Graduate Group, University of California, Davis 95616 \\ ${ }^{3}$ Department of Animal Science, Aarhus University, Tjele, Denmark, 8830
}

\begin{abstract}
Dairy calves often perform abnormal repetitive behaviors (ARBs) including tongue rolling and nonnutritive oral manipulation (NNOM) when opportunities to perform feeding behaviors are restricted. Many US dairy farms limit access to milk, a well-studied risk factor for ARBs. However, farms also commonly do not feed forage to young calves, and the motor patterns of oral ARBs resemble those necessary for acquiring and chewing solid feed. Our objective was to assess how access to hay from birth influenced time engaged in normal and abnormal oral behaviors across $24 \mathrm{~h}$. Holstein heifer calves were housed individually on sand bedding and fed ad libitum water and grain (control, $\mathrm{n}$ $=11$ ) or given additional access to hay (hay, $\mathrm{n}=11$ ) from birth. Calves were fed 5.7 to $8.4 \mathrm{~L} / \mathrm{d}$ (step-up) of milk replacer via a teat. At the start of step-down weaning ( $50 \pm 1 \mathrm{~d}$ ), all calves were given access to a total mixed ration. Feed and water intake were measured daily. Oral behaviors (eating, ruminating, sucking milk, drinking water, panting, grooming, tongue flicking, tongue rolling, and NNOM) were recorded by direct observation at wk 2, 4, 6, and 8 using 1-0 sampling at 1-min intervals for $24 \mathrm{~h}$. Grain, hay, and water intake increased over time in the preweaning period. One polydipsic calf regularly consumed $>10 \mathrm{~L}$ of water/d. During weaning, hay calves tended to consume increasingly more total mixed ration, significantly more water, and less grain than control calves. Access to hay led to more observations spent eating solid feed ( $7 \%$ vs. $5 \%$, mean percentage of intervals) and ruminating (24\% vs. $16 \%$ ) during the preweaning period compared with calves fed only grain, though control calves appeared to ruminate in absence of forage to re-chew. Rumination occurred, to a large extent, overnight. Hay calves also spent less time self-grooming (12\% vs. 14\%), tongue flicking (14\% vs. $18 \%)$, and performing NNOM (17\% vs. $21 \%)$ than
\end{abstract}

Received October 15, 2021.

Accepted December 28, 2021.

*Corresponding author: cbtucker@ucdavis.edu control calves. Although NNOM peaked around milk feedings, all 3 behaviors were performed throughout the day. Tongue rolling was rare across treatments, as was panting, which occurred most frequently around 1400 h. There were no behavioral differences during weaning (wk 8). Overall, we found that hay provision affected most oral behaviors that calves perform; it promoted natural feeding behaviors and reduced abnormal ones, suggesting hay should be provided. We also found that calves performed other behaviors, including polydipsia, repetitive grooming, and apparent sham rumination, that may suggest a degree of abnormality in these behaviors that has not been previously identified. These results highlight the importance of considering all oral behaviors to better understand calf welfare.

Key words: abnormal repetitive behavior, rumination, hay, oral behavior

\section{INTRODUCTION}

Dairy calves perform abnormal repetitive behaviors (ARBs), or behaviors that appear inappropriate and repetitive in motor pattern or goal (e.g., Garner, 2005), when natural feeding opportunities are reduced. Tongue rolling and nonnutritive behaviors, including crosssucking and oral manipulation of nonfeed items such as pen structures and bedding, are common in calves (e.g., Webb et al., 2015; Horvath and Miller-Cushon, 2017; Salter et al., 2021) and indicative of compromised animal welfare (Mason and Latham, 2004; Latham and Mason, 2010). An often-cited claim is that these ARBs stem from frustrated sucking motivation (Sambraus, 1985), as some are reduced when more opportunities to suck are provided (e.g., higher quantities of milk, Rushen and de Passillé, 1995; teat or slow-flow feeding, Hammell et al., 1988; Veissier et al., 2002; Salter et al., 2021), or when calves are weaned off of milk (e.g., cross-sucking in group-housed calves, Lidfors, 1993). However, ARBs are also reduced when calves are provided forage (e.g., Haley et al., 1998; Castells et al., 2012; Horvath and Miller-Cushon, 2017, 2019a). This is typically withheld in the United States early in life 
(provided around $36 \mathrm{~d}$, USDA, 2016) and not required before $14 \mathrm{~d}$ under EU legislation ("fibrous feed," European Council, 2008). Abnormal repetitive behaviors are seen in older animals when time spent processing solid feed, such as chewing and ruminating, is restricted by limited access to forage (Redbo et al., 1996; Redbo and Nordblad, 1997), and their form, particularly in tongue rolls or flicks, often resemble natural foraging patterns such as biting and curling the tongue to rip grass from pasture (Sambraus, 1985; Seo et al., 1998). Furthermore, time engaged in solid-feed processing typically takes $42 \%$ of a calf's daily time budget on pasture (Swanson and Harris, 1958) compared with only 3\% of time sucking from the dam (as reviewed by de Passillé, 2001). It is likely that restricting time engaged in natural ingestive behaviors overall, including chewing and ruminating, rather than only restricting sucking, plays a role in the development of ARBs.

The importance of food-processing behavior overall has historically been underestimated because studies assessing ARBs in calves often face 1 of 3 challenges. First, when forage is provided, it is often not offered at birth (e.g., Kooijman et al., 1991; Phillips, 2004; Castells et al., 2012). Calves will consume grass in pasture-based settings within the first few days of life (Swanson and Harris, 1958), and it is likely that calves in more barren environments will be motivated to explore potential feed items and eat forage equally soon after birth. Second, time performing certain foodprocessing behaviors is often not scored. Studies that provide hay often do not record time spent ruminating (e.g., Seo et al., 1998; Horvath and Miller-Cushon, 2017, 2019a), whereas those that do measure eating and ruminating do not evaluate ARBs (e.g., Swanson and Harris, 1958; Dennis et al., 2018). Similarly, investigations into the onset of abnormal sucking behaviors often do not report time spent nutritively sucking (e.g., Babu et al., 2004; Montoro et al., 2013; Webb et al., 2015). Finally, behavior is often not scored across 24 h (e.g., Bokkers and Koene, 2001; Hepola et al., 2006; Webb et al., 2015; Zhang et al., 2021), despite evidence that rumination happens disproportionately overnight (as reviewed by Beauchemin, 2018). It is instead often focused around milk feeding times (Babu et al., 2004; Montoro et al., 2013; Horvath and Miller-Cushon, 2017; Salter et al., 2021). These experimental choices likely mask the effect of solid-feed processing behaviors on ARBs, lending credence to the assumption that milk is their main driver.

Another challenge in understanding ARBs is that research overlooks other oral behaviors that calves perform. Calves also spend time drinking water, grooming, and performing tongue flicks up to the nose. These behaviors may be normal, motivated by thirst or par- ticulates in the hair (Panivivat et al., 2004) or nose (Meltzer and Githens, 1919), but may also stem from frustration of normal nutritive behaviors. For example, grooming is noted to be influenced by hay provision (e.g., increased: Horvath and Miller-Cushon, 2017; reduced: Horvath et al., 2020), whereas water intake is affected by milk provision (as reviewed by Jensen and Vestergaard, 2021). However, grooming has also been positively correlated with tongue rolling in heifers (Seo et al., 1998), and excessive water drinking, or polydipsia, is seen in other species in situations where feeding behavior is thwarted (e.g., gerbils, Roper, 1978; broiler breeders, Savory et al., 1992; sows, Robert et al., 1993). Taken together, these examples illustrate that some behaviors may be expressed normally in some contexts but may be heightened in other situations where welfare may be compromised, suggesting a clear division between normal and abnormal behaviors may not exist. However, these other oral behaviors are not always evaluated in studies investigating ARBs (e.g., Kooijman et al., 1991; Bokkers and Koene, 2001; Margerison et al., 2003).

We thus set out to evaluate how access to hay from birth affected time engaged in all oral behaviors performed by individually housed dairy calves across 24 $\mathrm{h}$ throughout the milk-fed period. We expected that solid-feed intake would increase as calves aged; however, because hay requires more chewing and rumination than grain (Khan et al., 2011; Castells et al., 2012), we predicted that calves fed hay would spend increasingly more time chewing and ruminating than calves fed only grain and milk. We predicted that this increased engagement would lead to them performing fewer ARBs, including nonnutritive oral manipulation (NNOM) and tongue rolling, particularly as they aged. We also predicted that some behaviors, such grooming, tongue flicks, and water drinking, would be performed more by control calves. Panting, an oral behavior commonly considered to reflect heat stress (e.g., Tresoldi et al., 2016) but is understudied in calves, was also measured due to the dearth of information about it.

\section{MATERIALS AND METHODS}

This experiment was conducted from July to October, 2018, at the University of California, Davis Dairy Facility. All procedures were approved by the University of California, Davis Institutional Animal Care and Use Committee (protocol \#20466).

\section{Animals and Housing}

We enrolled all healthy female Holstein calves born between July 20 and September 1 at the University of 
California, Davis Dairy facility, for a total of 22 calves. They were housed individually in outdoor plastic hutches $(2 \times 1.5 \mathrm{~m}$, length $\times$ depth $)$ with an attached wire-fenced pen $(2 \times 1.5 \times 0.9 \mathrm{~m}$, length $\times$ depth $\times$ height). Hutches and pens were spaced $\sim 0.5 \mathrm{~m}$ apart, allowing calves to touch the muzzle of neighboring animals. The enclosures were bedded with sand $\sim 12$ to 17 $\mathrm{cm}$ deep that was spot-cleaned daily and topped-up as needed. The sand was covered with perforated rubber mats from d 0 to $5 \pm 1$ to limit unintentional inhalation of sand particulate (Supplemental Figure S1, https:// doi.org/10.5281/zenodo.5553444, Tucker et al., 2022a). Sand was used to prevent fibrous bedding consumption (Phillips, 2004).

Calves received colostrum twice a day for $5 \mathrm{~d}$, with each calf consuming $18.5 \pm 3.5 \mathrm{~L}$ (mean $\pm \mathrm{SD}$ ) total. Colostrum meals were fed via a bottle and rubber teat (Connewango) or rarely by an esophageal tube feeder (2.7\% of all colostrum feedings). From 5 to $13 \mathrm{~d}$ of age, calves were fed $1.9 \mathrm{~L}$ of milk replacer $(26 \% \mathrm{CP}, 16 \%$ fat, $15 \%$ total solids, mixed as indicated at a rate of $142 \mathrm{~g} / \mathrm{L}$ of hot water; Calva Products Inc.) at each of 3 daily meal as follows: 0645, 1245, and $1845 \mathrm{~h}$. From 14 to $23 \mathrm{~d}$ of age, calves received $2.4 \mathrm{~L}$ of milk replacer at each of the 3 meals, and from 24 to $49 \pm 1 \mathrm{~d}$ of age, $2.8 \mathrm{~L}$ of milk replacer per meal. All milk replacer meals were fed via a bottle and rubber teat following farm protocol. Bottles were available for 15 min per feeding, as tracked with digital timers (Lavatools KT1 Digital Kitchen Timer and Stopwatch), in a metal holder (Hatfield Manufacturing Inc.) $0.8 \mathrm{~m}$ above the ground at the front of the pen. Weaning began at $50 \mathrm{~d} \pm 1 \mathrm{~d}$ in a $10-\mathrm{d}$ step-down process. On d 0 to 4 of weaning, the 0645 $\mathrm{h}$ meal was removed, and on $\mathrm{d} 5$ to 9 , the $1245 \mathrm{~h}$ meal was removed. Calves were fully weaned at $60 \mathrm{~d} \pm 1 \mathrm{~d}$.

All calves were disbudded at wk 1 to $2(\mathrm{n}=7 ; 38.3$ $\mathrm{kg})$ or wk 4 to $5(\mathrm{n}=15 ; 39.2 \mathrm{~kg})$ as part of a separate experiment balanced on feeding treatment and birth weight. Calves were given a cornual nerve block with 5 to $7 \mathrm{~mL}$ of buffered lidocaine hydrochloride on each side of the head, and hair over the horn bud was trimmed before application of a disbudding iron until a copper ring formed. Oral meloxicam $(0.5-1 \mathrm{mg} / \mathrm{kg}$ of BW) was provided to all calves after disbudding. All calves were vaccinated with Bovishield 5 at 21 and $40 \mathrm{~d}$, Spirovac at $30 \mathrm{~d}$, and One Shot at $40 \mathrm{~d}$ (all Zoetis Inc.). Health was monitored daily following a modified Wisconsin Calf Health Scorecard (University of Wisconsin School of Veterinary Medicine, Supplemental Table S1, https: //doi.org/10.5281/zenodo.5553444, Tucker et al., 2022a). A total of 5 observers were trained to $>80 \%$ reliability (Kendall's W) using 40 photo tests for nasal discharge, ocular discharge, ear position, and feces; 10 photos per score were presented in a randomized order.
Scores above zero for cough, respiratory, and attitude were rarely observed and not common enough to be able to calculate Kendall's W. Rectal temperature was taken if calves had a combined score of 3 or higher on the other measures. All calves received $2 \pm 2.7$ (mean $\pm \mathrm{SD}$ ) treatments of $1.9 \mathrm{~L}$ of electrolytes via a bottle and teat over the course of the experiment. Two calves were given a shot of tetracycline over the course of the experiment to treat early cases of pink eye.

\section{Experimental Design}

At birth, calves were assigned to 1 of 2 treatments, alternating based on birth order with adjustments made to balance for weight as follows: control $(\mathrm{n}=11 ; 38.7$ $\pm 1.4 \mathrm{~kg})$, and hay $(\mathrm{n}=11 ; 39.0 \mathrm{~kg} \pm 1.5 \mathrm{~kg})$. Calves assigned to the control treatment received ad libitum water and starter (Table 1; Starter Calf Feed 901033, Associated Feed and Supply Co.; Supplemental Figure S2, https://doi.org/10.5281/zenodo.5553444, Tucker et al., 2022a) by bucket from birth. Calves assigned to the hay treatment received ad libitum water, starter, and mountain grass hay (mix of orchard, Dactylis glomerata, and fescue, Festuca arundinacea; Higby's Country Feed; Supplemental Figure S2) chopped through a 2.54-cm screen (Table 1, Table 2) by bucket from birth. All calves always had the following 3 buckets available: grain, water, and hay or empty bucket (control), left to right (Supplemental Figure S3, https://doi.org/ 10.5281/zenodo.5553444, Tucker et al., 2022a). The assigned feeding method continued through the preweaning period. Beginning at weaning (d $50 \pm 1$ ), ad libitum TMR (Table 1, Table 2; alfalfa, almond hulls, cottonseed, corn, barley, beet pulp) was provided for all calves, as per farm protocol, in place of the hay or empty bucket for hay and control treatments, respectively.

\section{Data Collection}

Feed Intake. Solid-feed intake was recorded by providing pre-weighed fresh feed daily at $0600 \mathrm{~h}$ and subtracting the refusals on the following day at 0600

Table 1. Chemical composition of solid feeds (mean $\pm \mathrm{SD}$, reported as $\%$ of DM)

\begin{tabular}{lrrr}
\hline $\begin{array}{l}\text { Chemical } \\
\text { composition }\end{array}$ & \multicolumn{1}{c}{ Grain } & Hay & \multicolumn{1}{c}{ TMR } \\
\hline DM & $86.8 \pm 0.6$ & $92.2 \pm 1.2$ & $89.3 \pm 0.7$ \\
CP & $22.1 \pm 1.8$ & $10.5 \pm 0.4$ & $20.6 \pm 1.4$ \\
ADF & $7.1 \pm 0.7$ & $36.6 \pm 0.8$ & $21.8 \pm 0.8$ \\
NDF & $12.2 \pm 0.6$ & $57.5 \pm 1.2$ & $31.3 \pm 0.8$ \\
Ash & $8.2 \pm 0.5$ & $7.9 \pm 0.4$ & $7.5 \pm 1.1$ \\
TDN & - & $59.8 \pm 0.5$ & $69 \pm 2.2$ \\
\hline
\end{tabular}


$\mathrm{h}$ from the initial provisions (GBK16a Bench Check Weighing Scale, 8,000 g limit, $0.1 \mathrm{~g}$ readability, Adam Equipment Inc.). Solid-feed levels were checked at each milk meal and added as needed to maintain ad libitum levels. Calves were fed to at least $15 \%$ more than the previous day's intake throughout the experiment, with a minimum of $500 \mathrm{~g}$ of grain and $150 \mathrm{~g}$ of hay provided at all feedings. Water orts were recorded, and fresh measured water provided at each of the milk meals. If feces were present in any of the buckets, intake data for that calf for that day were discarded. Girth circumference measurements were taken once weekly during the experimental period and converted to kilograms (Heinrichs et al., 1992). Differences between start and end measures from each week were calculated and divided by 7 to determine ADG.

To calculate DM and nutritional protein of the feed, fresh feed was sampled once a week and sent to Cumberland Valley Analytical Services Inc. for analysis of DM [1358C; method 930.15 (AOAC International, 2000)], ash [5358C; method 942.05 (AOAC International, 2000)], ADF [method 973.18 (AOAC International, 2000)], NDF with heat-stable a-amylase and sodium sulfite (Van Soest et al., 1991), and $\mathrm{CP}[\mathrm{N} \times 6.25$; method 990.03 (AOAC International, 2000); Leco FP528 Nitrogen Analyzer, Leco]. The nutrient content of the solid feed is reported in Table 1. Samples of daily orts were taken per calf and combined weekly to determine DM. These combined samples were oven-dried at $100 \mathrm{C}$ for $15 \mathrm{~h}$ and weighed (AG104, $101 \mathrm{~g}$ limit, $0.1 \mathrm{mg}$ readability scale, Mettler Toledo, LLC) to determine DM content.

Behavioral Observations. Calf behavior was recorded using 1-0 sampling at 1-min intervals for a continuous $24 \mathrm{~h}$ beginning at $0600 \mathrm{~h}$. Each calf was observed during the preweaning period in wk 2,4 , and 6 of age (17 $\pm 3 \mathrm{~d}, 31 \pm 3 \mathrm{~d}$, and $45 \pm 3 \mathrm{~d}$, respectively). Calves were also observed during the weaning period on d 6 (calf age $=56 \pm 1 \mathrm{~d}$ ), which was $1 \mathrm{~d}$ after the second milk feeding was removed. The following behaviors were recorded as present or not present every 1 min using the Animal Behavior Pro app (Newton-Fisher, 2012) with continuous countdown timers (Pebble Technology Corp., Fitbit): drinking water, eating hay or grain,

Table 2. Particle size of mountain grass hay and TMR (mean \pm SD, reported as \% of diet; Penn State Particle Separator)

\begin{tabular}{lrc}
\hline Particle size & Mountain grass hay & TMR \\
\hline$>1.9 \mathrm{~cm}$ & $54.9 \pm 9.9$ & $17.5 \pm 5.3$ \\
$0.79-1.9 \mathrm{~cm}$ & $5.0 \pm 1.2$ & $19.7 \pm 2.7$ \\
$0.41-0.79 \mathrm{~cm}$ & $9.6 \pm 2.6$ & $26.1 \pm 2.1$ \\
$<0.41 \mathrm{~cm}$ & $28.9 \pm 7.0$ & $35.9 \pm 4.4$ \\
\hline
\end{tabular}

grooming, NNOM, panting, ruminating, sucking liquid (milk, electrolytes), tongue flicks, and tongue rolling (Table 3, Supplemental Videos 1-12, https://doi.org/ 10.5281/zenodo.5553444, Tucker et al., 2022a). One observer scored 1 to 2 calves in neighboring hutches at a time. A total of 18 observers were used. All observers were trained to reliability $\geq 75 \%$ (Cohen's kappa; irr package version 0.84.1, Gamer et al., 2019) for all behaviors using live scoring sessions of 1-0 sampling for a minimum of $2 \mathrm{~h}$ across $2 \mathrm{~d}$. Tongue rolling and panting were rare and were assessed using a 30-question video test (15 yes, 15 no). Tongue flick reliability was $\geq 75 \%$, whereas all other behaviors were $\geq 80 \%$. Observers were not blind to treatment as feed availability could not be masked.

\section{Statistical Analysis}

Data and RMarkdown files for all analyses, figures, and supplemental material are available online in the Dryad repository (code: https://doi.org/10.5281/zenodo.5553442, Tucker et al., 2022b; Supplemental Figures S1-S5, Tables S1-S3, and Videos 1-12, https://doi.org/10.5281/zenodo.5553444, Tucker et al., 2022a).

Some intake data were excluded $(9.8,22.9,7.4$, and $15.7 \%$ of calf-day values for grain, hay, water, and TMR, respectively) due to contamination with feces or saliva and spillage by calves, or because calves showed signs of illness that day (scored a combined 3 or above on health scoring; 17 calves total for $2.7 \%$ of calf-days). Data were also excluded if intake could not be calculated on a DM basis, which was due to errors in drying individual ort samples. Of the $22.9 \%$ of calf-day values for hay that were excluded, most (81\%) occurred within the first $3 \mathrm{wk}$ when consumption was low. One day of behavioral data was excluded in wk 6 as 1 calf (hay treatment) was not observed due to human error.

Data were separated by age into preweaning (intake data: 0-50 $\pm 1 \mathrm{~d}$, behavioral data: wk 2, 4, 6) and weaning (intake data: $50-60 \pm 1 \mathrm{~d}$, behavioral data: wk 8) periods. Statistical analyses were performed using $R$ (version 4.0.3; https://www.r-project.org/) on macOS Big Sur 10.16 via RStudio (version 1.2.5033) with calf as the experimental unit. All model fits were checked for normality and homogeneity of variance using QQ plots and plots of residual versus fitted values (plot, boxplot, resid functions in base $\mathrm{R}$, ggpubr package version 0.4.0, Kassambara, 2020; DHARMa package version 0.3.3.0, Hartig, 2021); unless stated otherwise, all model assumptions were met.

Feed Intake. During the preweaning period, grain and hay intake data were averaged by week $(0,1,2$, 
Table 3. Behaviors recorded during continuous 24 -h observations ${ }^{1}$

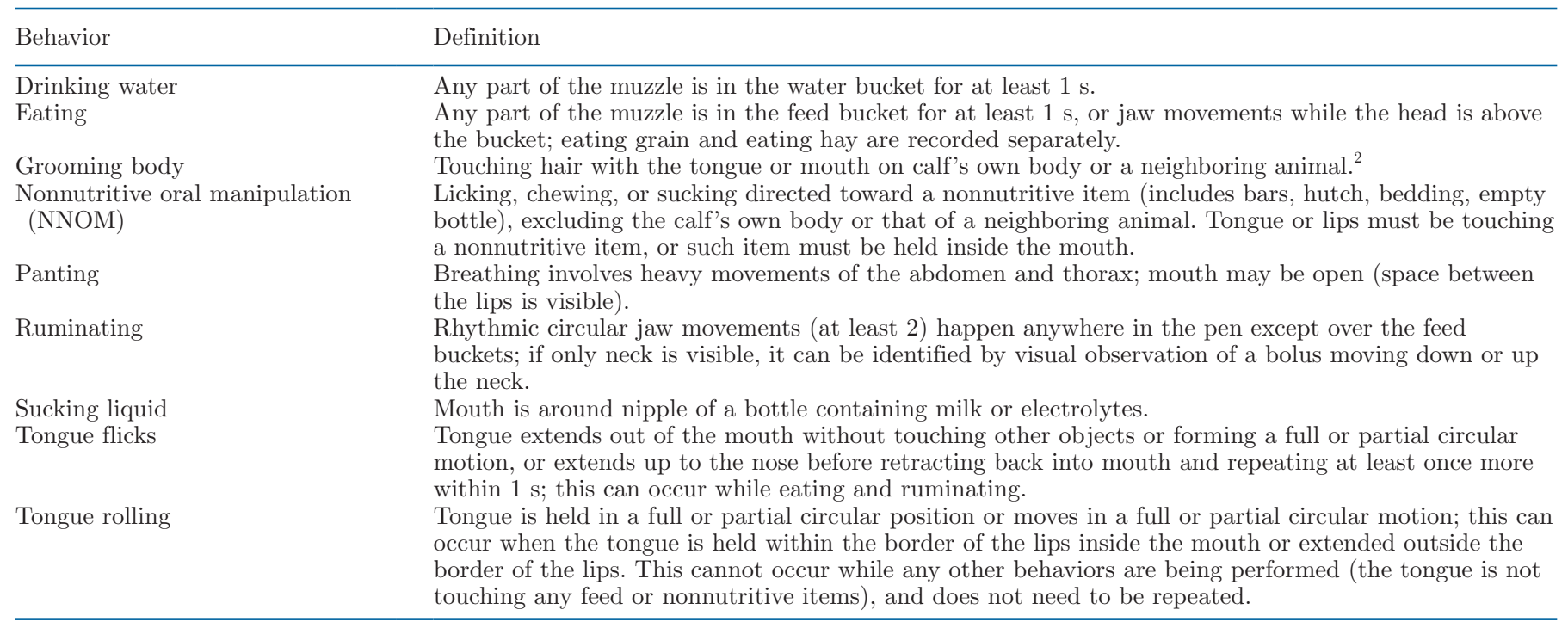

${ }^{1}$ For all relevant definitions, muzzle is defined as from the bottom of the eyes to the end of the mouth. See Supplemental Videos 1-12 (https:// doi.org/10.5281/zenodo.5553444, Tucker et al., 2022a) for examples.

${ }^{2}$ Licking a neighboring animal was very uncommon due to the position and spacing of the hutches.

$3,4,5,6)$ and modeled with a linear mixed model using the restricted maximum likelihood method with an identity variance structure to account for heterogeneous variance across weeks (lme4 package version 1.1-26, Bates et al., 2015). Week was treated as a continuous variable. Week, treatment, and the interaction between week and treatment were fixed effects, whereas calf was a random effect.

Water intake in the preweaning period was fit with a linear mixed model using the restricted maximum likelihood method and an identity variance structure across treatment. This model did not fully address the unequal variance, based on the normalized residuals, because of 1 consistently extreme outlier in the hay treatment. A regular linear mixed model was run excluding this calf, 2943, from the data. The results from both the regular linear mixed model (excluding the outlier) and the identity variance model (including the outlier) are presented.

During the weaning period, intake was assessed by day due to the step-down nature of weaning; age in days was treated as a continuous variable. Grain, TMR, and water intake were modeled with linear mixed models (lme 4 package version 1.1-26, Bates et al., 2015) with age in days, treatment, and the interaction between days and treatment as fixed effects and calf as a random effect.

$A D G$. ADG during the preweaning period was modeled with a linear mixed model (lme 4 package version 1.1-26, Bates et al., 2015) with week, treatment, and the interaction between week and treatment included as fixed effects and calf as a random effect. The ADG from wk 0 and 7 were not included in the model as not all calves had a wk 0 or 7 calculation for ADG, based on when they were first measured (wk 0) or weaned (wk 7), and early life stress and adjustment to the environment can lead to growth checks (e.g., Chapman et al., 2016). All calves thus had 6 to 7 ADG calculations, with the final preweaning measurement occurring on $\mathrm{d}$ $45 \pm 2$.

The ADG during weaning was not assessed, as calves only had 1 to 2 measurements during this period, and measurements were not taken at a consistent point in the step-down process for all calves. Instead, final weight (measured on $57 \pm 2 \mathrm{~d}$ ) and overall ADG across the entire trial period were assessed using a 2-tailed unpaired $t$-test (t.test function in base $\mathrm{R}$ ).

Behavioral Observations. A generalized linear mixed model (glmmTMB package version 1.0.2.1.3, Brooks et al., 2017) with a $\beta$ distribution was fitted to analyze proportion of time engaged in each behavior during the preweaning period. Week, treatment, and the interaction between week and treatment were included as fixed effects, and calf was a random effect. Week was treated as a categorical variable as observations were conducted at 3 distinct time points (wk 2, 4, and 6 ). Tongue rolling and panting were rare and were not analyzed with a model. Behavioral data during weaning (wk 8) were compared between treatments using a 2-tailed, unpaired $t$-test (t.test function in base $\mathrm{R}$ ). Behavioral data are reported as percentages hereafter in the text to facilitate readability; supplemental material 
and raw data (code: https://doi.org/10.5281/zenodo .5553442 ; Supplemental figures and tables: https://doi .org/10.5281/zenodo.5553444) are expressed as proportions.

All intake and behavior model fits were assessed with an ANOVA (type III SS; car package version 3.0-10, Fox and Weisberg, 2019) to obtain $P$-values. Individual significant fixed effects are only reported if the interaction term was not significant. The interaction term is only reported if significant $(P<0.05)$.

\section{RESULTS}

\section{Intake}

During the preweaning period $(\mathrm{d} 0-50 \pm 1)$, there was a significant effect of week on grain $(P<0.001$; Figure 1) and hay consumption $(P<0.001$; Figure 1 ; test statistics, df, and $P$-values reported in Supplemental Table S3, https://doi.org/10.5281/zenodo.5553444). On average, calves consumed $2.8 \pm 0.05 \mathrm{~L}$ of water per day during the preweaning period. Individual intake varied from 0.15 to $20.35 \mathrm{~L}$ of water in a single day. Only 1 calf (2943; hay treatment) drank more than 10 $\mathrm{L} / \mathrm{d}$ in any given day during the preweaning period, with $35 \%$ of her water intake days above $10 \mathrm{~L}$, whereas 7 additional calves drank more than $10 \mathrm{~L} / \mathrm{d}$ during step-down weaning. Using all preweaning water intake data, there was a week by treatment interaction $(P=$ 0.003 ) for control calves increasing water intake more over time than hay calves. However, when calf 2943 was removed, only week had an effect, with water intake increasing equally over time for both treatments $(P<$ 0.001, Figure 1).

In the weaning period ( $\mathrm{d} 50-60 \pm 1)$, all calves increased feed and water intake over time $(P<0.001)$. However, hay calves tended to consume increasingly more TMR $(P=0.052$; Figure 1$)$ and consumed significantly more water $(P=0.007$; Figure 1$)$ than control calves as weaning continued, whereas control calves consumed increasingly more grain than hay calves $(P$ $=0.042 ;$ Figure 1$)$.

\section{ADG}

Hay provision did not influence ADG during the preweaning period (hay: $0.72 \pm 0.06 \mathrm{~kg} / \mathrm{d}$, control: $0.70 \pm$ $0.07 \mathrm{~kg} / \mathrm{d}, P=0.583)$, with calves of both treatments increasing ADG over time $(P<0.001)$. Overall ADG across the trial was similar across treatments (hay: 0.74 $\pm 0.03 \mathrm{~kg} / \mathrm{d}$, control: $0.73 \pm 0.03 \mathrm{~kg} / \mathrm{d}, P=0.692$ ), as was final BW (hay: $81 \pm 2 \mathrm{~kg}$, control: $80 \pm 2 \mathrm{~kg}, P=$ 0.787).

\section{Oral Behaviors}

During the preweaning period $(\mathrm{d} 0-50 \pm 1)$, there was a significant effect of hay provision on percentage of observations where calves were performing oral behaviors. Hay calves ruminated in more observations compared with control calves $(P<0.001$, Figure 2 ; test statistics, df, and $P$-values reported in Supplemental Table S3), though all calves, regardless of treatment, were ruminating by wk 2 (mean percentage of intervals \pm SE; $20.2 \pm 1.6 \%$ ). Rumination was consistent across weeks $(P=0.904)$ and was performed throughout the day and night (Figure 3). Hay calves were eating grain in fewer observations than control calves $(P=0.031)$, though they spent more time eating overall than control calves when time consuming forage was included $(P<0.001$, Figure 2). Overall, all calves increased percentage of observations eating $(P<0.001)$, eating grain $(P<0.001)$, and eating forage $(P<0.001)$ as they aged. Time spent eating solid feed and sucking milk peaked around milk delivery (Figure 3 ). There was no treatment effect on percentage of observations sucking milk $(P=0.733$, Figure 4$)$. All calves increased percentage of observations sucking milk from wk 2 to $4(P<0.001)$, though there was no difference from wk 4 to 6 . There was a tendency for treatment to affect time spent drinking water across weeks $(P=0.087$, Figure 4). All calves spent fewer observations drinking water from wk 2 to 4 , but hay calves tended to increase observations spent drinking from wk 4 to 6 , whereas control calves did not.

Control calves consistently engaged in more selfgrooming $(P=0.026$, Figure 2$)$, tongue flicking $(P=$ 0.016 , Figure 2$)$, and NNOM $(P=0.002$, Figure 2$)$ than hay calves. There was no effect of week (grooming: $P$ $=0.334$, tongue flicks: $P=0.486$, NNOM: $P=0.187)$. Both grooming and tongue flicks were performed across $24 \mathrm{~h}$ (Figure 3 ). The NNOM was high around milk feedings but was observed throughout the day and night (Figure 3). During the weaning period ( $56 \pm 1 \mathrm{~d}$ ), all oral behaviors were performed for similar percentages of intervals between both treatments (Figure 2).

All but 3 calves ( 1 hay, 2 control) tongue rolled at least once during 1 of the $4 \mathrm{wk}$, though overall tongue rolling was rare (hay: $0.1 \pm 0.03 \%$, control: $0.3 \pm 0.1 \%$, Supplemental Figure S4, https://doi.org/10.5281/ zenodo.5553444). Calves that tongue rolled performed this behavior for 0.07 to $2.9 \%$ of observations, and the 4 calves who tongue rolled the most (for $>1 \%$ of observations in a given day) were all control calves. Fewer calves tongue rolled in wk 2 (4 calves) than in wk 4 to 8 (wk 4: 11 calves; wk 6-8: 12 calves each), but calves did not consistently tongue roll each subsequent 


\section{Control $=$ Hay}

a) Hay (kg)

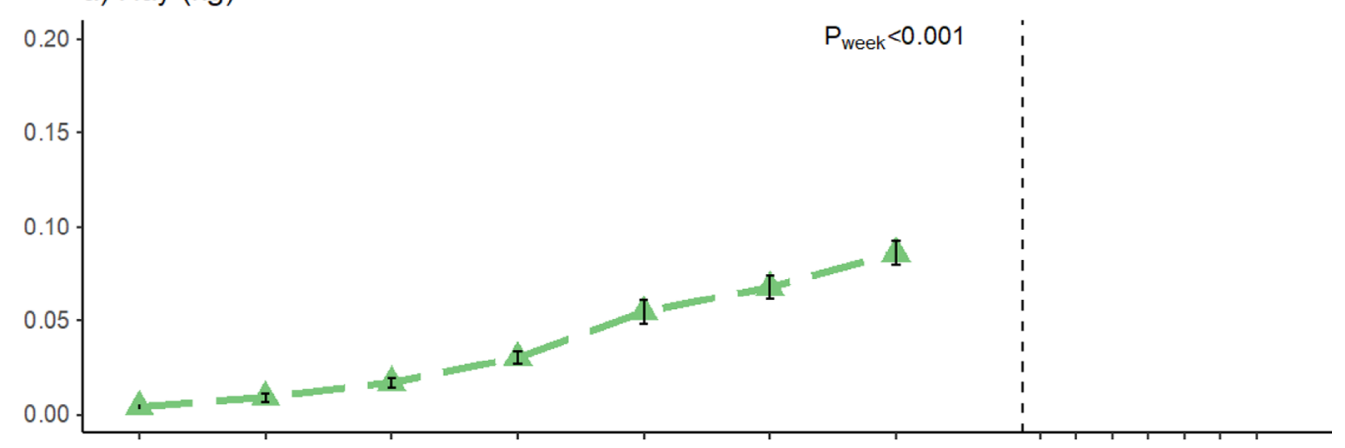

b) TMR (kg)

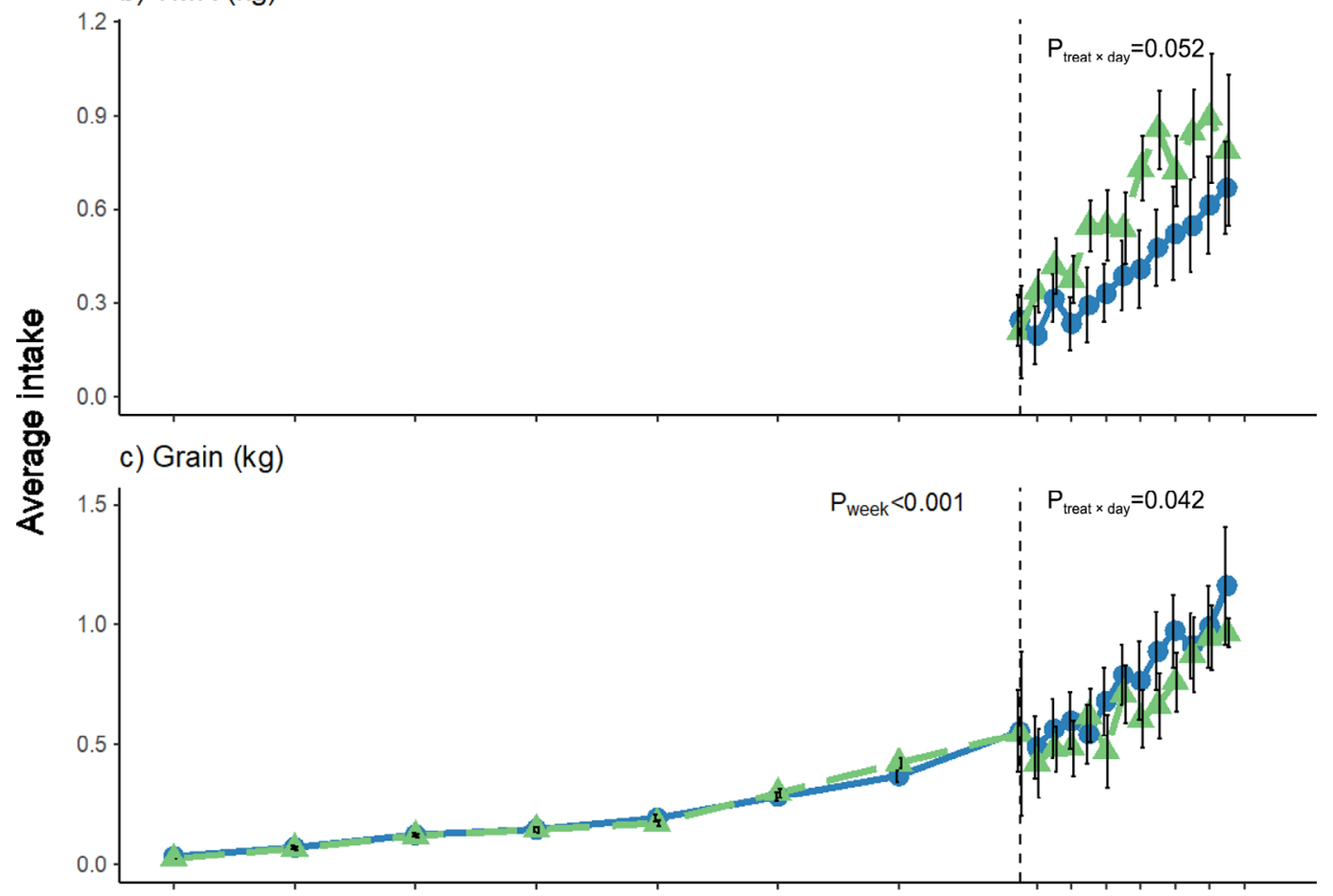

d) Water (L)

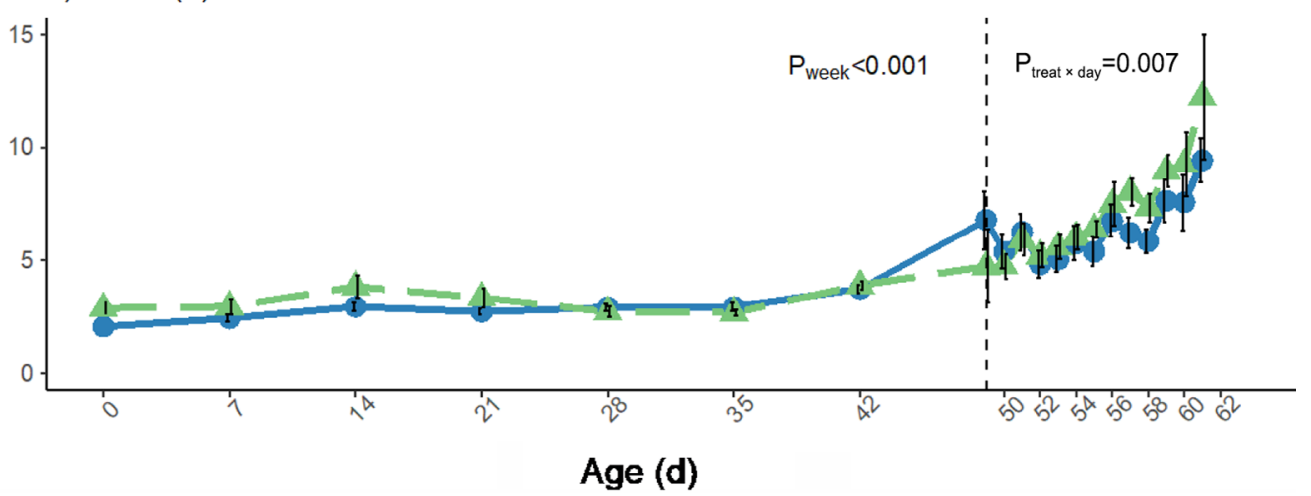

Figure 1. Feed and water intake values throughout the treatment period of calves fed a diet of starter grain and milk replacer from birth (control) or a control diet with additional mountain grass hay from birth (hay). There was TMR available for all calves at the start of step-down weaning $(50-60 \pm 1 \mathrm{~d})$, as indicated by the dashed line. Data are summarized by treatment and averaged by 7 -d period across the preweaning period, and by day during step-down weaning. Error bars represent SE. $P$-values $<0.1$ are reported for week (preweaning) or day (weaning), treatment, or interactive effects. 
Control Hay

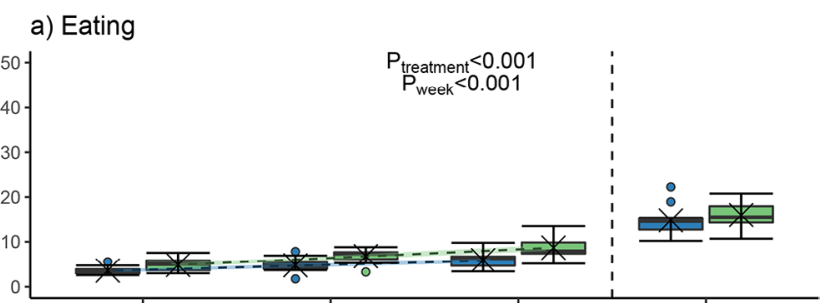

b) Ruminating
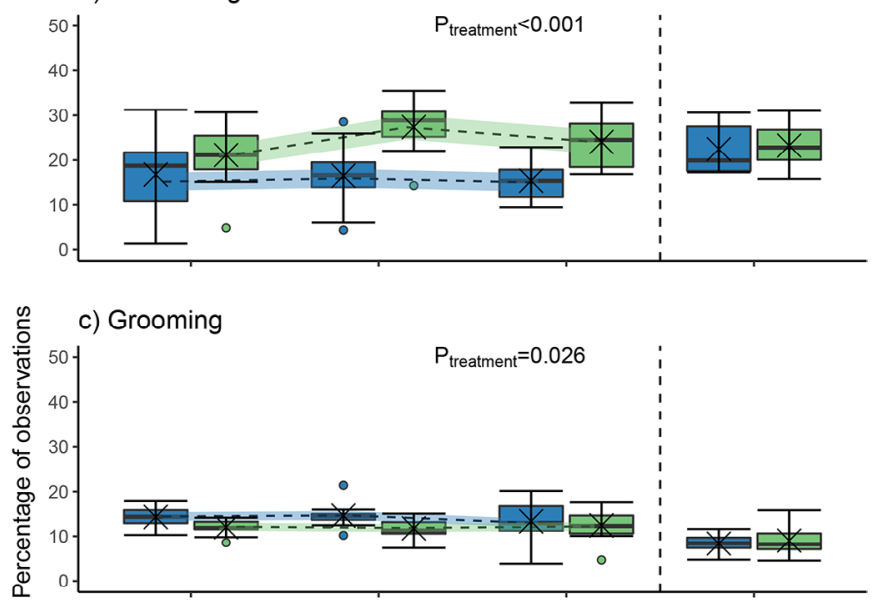

d) Tongue flicks

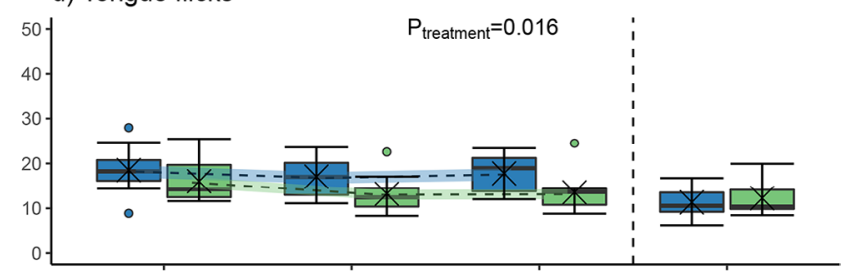

e) Nonnutritive oral manipulation

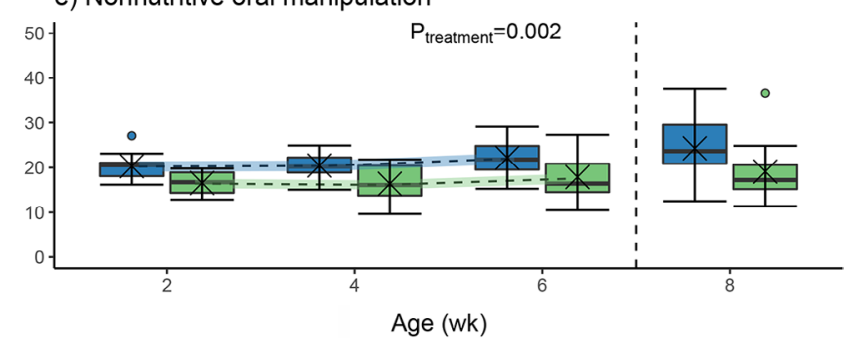

Figure 2. Mean percentage of intervals across $24 \mathrm{~h}$ engaged in eating (grain, hay, or both), ruminating, grooming, tongue flicks, and nonnutritive oral manipulation of calves fed a control diet of starter grain and milk replacer from birth (control) or a control diet with additional mountain grass hay from birth (hay). There was TMR available for all calves at the start of step-down weaning (50-60 $\pm 1 \mathrm{~d})$, as indicated by the dashed line. Data were collected via 1-0 live sampling at 1-min intervals for a continuous $24 \mathrm{~h}$ in wk $2,4,6$, and 8 and are summarized by treatment and week. Boxplots represent the median (black line within box) and first and third quartiles (25 and $75 \%$ of data). Whiskers extend to the lowest and highest values that are not outliers (values that are $1.5 \times$ the interquartile range); outliers (o) and means $(\mathrm{x})$ are also presented. Model predicted estimates are represented by dotted lines (means) and shaded ribbons (SE). $P$-values $<0.1$ are reported for week (preweaning only), treatment, or interactive effects. week after first performing the behavior (Supplemental Figure S4). Tongue rolling occurred throughout the day (Supplemental Figure S5, https://doi.org/10.5281/ zenodo.5553444). Panting was performed by 15 calves infrequently across all 4 weeks (hay: $1.1 \pm 0.5 \%$, control: $1.2 \pm 0.6 \%)$. Panting was most common in wk $2(9$ calves) and around warmer times of the day (e.g., 1400 h) across weeks $(6.2 \pm 5.1 \%)$.

\section{DISCUSSION}

\section{Ingestive Behavior}

Hay consumption did not reduce grain intake or ADG. Calves consumed an average of $0.18 \mathrm{~kg}$ of grain/d, regardless of treatment, and $0.046 \mathrm{~kg}$ of hay/d throughout the preweaning period, both of which are higher than in other studies conducted in similar settings. Calves will consume 0.09 to $0.11 \mathrm{~kg}$ of grain/d if they have access to a secondary food source, such as forage (Khan et al., 2011; Terré et al., 2015; Horvath and Miller-Cushon, 2017) or ad libitum milk (Appleby et al., 2001; Jasper and Weary, 2002), and 0.023 to 0.03 $\mathrm{kg}$ of hay/d when individually housed and fed below ad libitum milk levels (e.g., Jasper and Weary, 2002; Terré et al., 2015; Horvath and Miller-Cushon, 2017). Calves chose to consume hay at a rate of $20 \%$ of their total daily solid-feed intake, which is higher than many findings when milk is provided at less than ad libitum levels (e.g., 13-15\% voluntary inclusion, Castells et al., 2012; Horvath and Miller-Cushon, 2017, 2019a) but not all (e.g., 20\%, Khan et al., 2011).

Overall, our higher-than-normal solid-feed intake and hay inclusion rate could be due to provision of ad libitum water, which can encourage higher grain consumption than calves who have no or limited access to water (Kertz et al., 1984) or measurement gaps in other studies. Hay, for example, is not always reliably measured in young calves due to challenges associated with tracking small intake values (Jasper and Weary, 2002; Khan et al., 2011; Rosenberger et al., 2017). However, this solid-feed intake could also stem from limited milk provision. Calves will drink 9 to $12 \mathrm{~L}$ of milk/d if given the chance (Jasper and Weary, 2002). Therefore, the milk allowance in our experiment (5.7-8.4 L/d; $15 \%$ $\mathrm{BW}$ ), although greater than the standard $10 \% \mathrm{BW}$ provision, may have still left calves hungry, resulting in increased consumption to make up the deficit. In accordance with increased solid-feed consumption over time, ADG also increased over the preweaning period, as is well-established in growing calves (Hill et al., 2008). Gains during this period were similarly high $(0.83 \mathrm{~kg} / \mathrm{d})$ as in studies where ad libitum milk was provided (e.g., $0.85 \mathrm{~kg} / \mathrm{d}$, Appleby et al., 2001; 0.78 


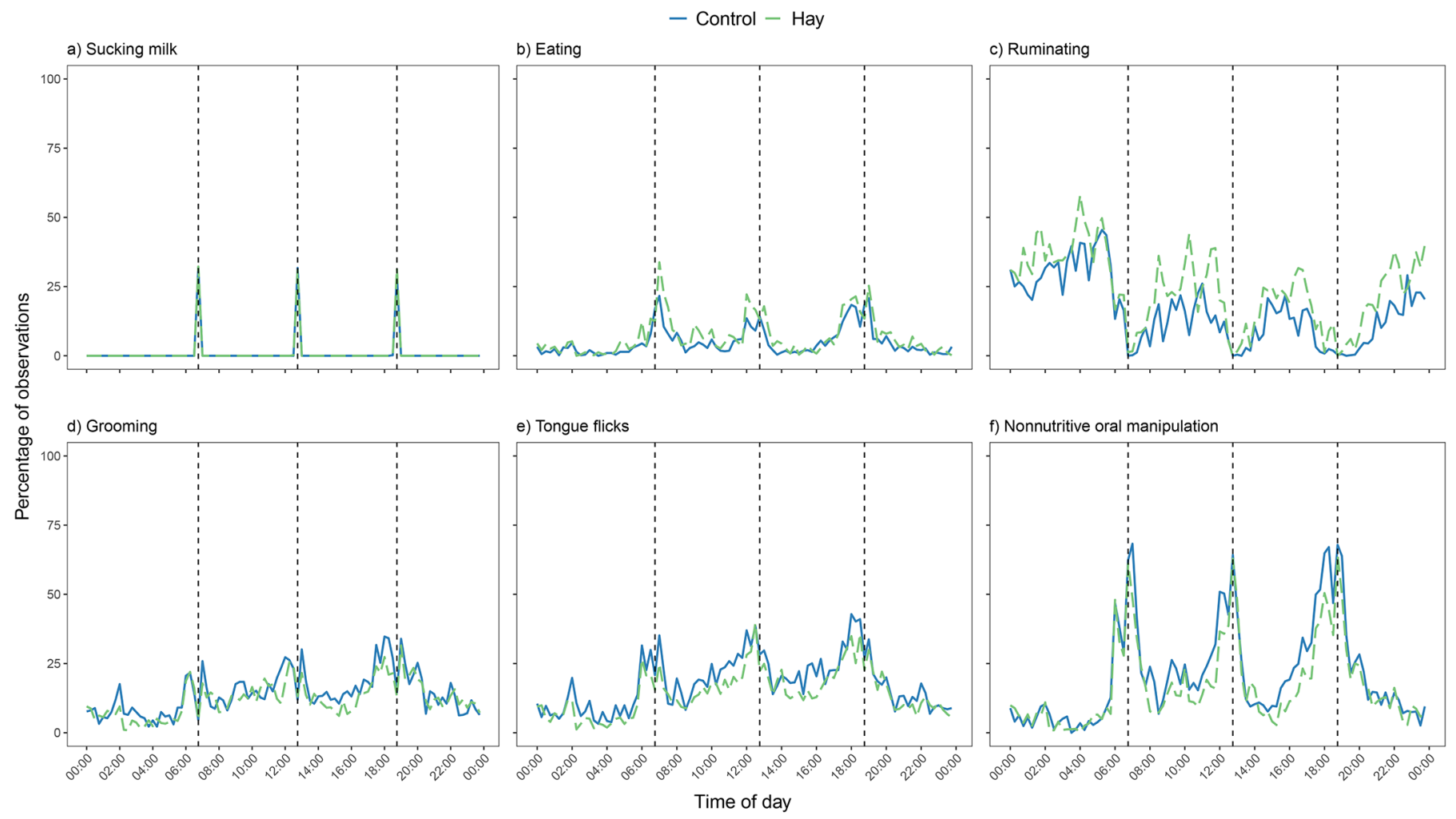

Figure 3. Circadian pattern of behavior obtained from 1-0 sampling at 1-min intervals throughout the preweaning period for calves fed a control diet of starter grain and milk replacer from birth (control) or a control diet with additional mountain grass hay from birth (hay). Data were averaged across wk 2, 4, and 6 by treatment at 15-min intervals. Dashed lines represent the start of milk feeding at 0645,1245 , and 1845 h. Bottles were available for $15 \mathrm{~min}$ at each feeding.

$\mathrm{kg} / \mathrm{d}$, Jasper and Weary, 2002; $0.65 \mathrm{~kg} / \mathrm{d}$, Horvath and Miller-Cushon, 2017).

Hay calves also increased time spent chewing and ruminating compared with calves fed only grain. Hay requires more oral processing and motor skills than grain (Arnold and Maller, 1977; Khan et al., 2011; Castells et al., 2012) and thus increases overall chewing time (Horvath and Miller-Cushon, 2017; Horvath et al. 2020). Daily consumption of even low levels of forage in early development can improve the rumen environment (Castells et al., 2013; Terré et al., 2015), making it easier for calves to handle more complex or larger amounts of feed, and stimulate rumination (Swanson and Harris, 1958). Rumination is rarely recorded in young calves, but has been reported to start around 2 wk of age on average (onset at 9-28 d) for up to $15 \%$ of the day in the first month of life (Wang et al., 2022). This is noted to increase as calves age (Margerison et al., 2003), leveling off at around 20 to $23 \%$ of the day during the milk-fed period (dairy calves at $5 \mathrm{wk}$, Swanson and Harris, 1958; veal calves at 3 mo, Webb et al., 2014). Hay calves similarly ruminated in 21 to $27 \%$ of observations consistently as early as 2 wk of age. This earlier onset could reflect our robust 24-h sampling, as rumination is disproportionately performed during the night (as reviewed by Beauchemin, 2018) and is likely misrepresented when only a subset of daylight hours are scored (Margerison et al., 2003).

Increased processing experience in calves fed hay may also improve transition to a forage-based diet at weaning. Although all calves increased solid-feed intake over the weaning period, as is common when a step-down process is used (Sweeney et al., 2010; Khan et al., 2011; Castells et al., 2013), hay calves consumed 0.2 to $0.4 \mathrm{~kg}$ of $\mathrm{TMR} / \mathrm{d}$ more and 0.05 to $0.2 \mathrm{~kg}$ of grain/d less than control calves as weaning progressed. Similar effects of preweaning feed exposure affecting later feeding behavior in ruminants have been found for feed sorting (Miller-Cushon et al., 2013), preferences (Nolte et al., 1990), and overall intake (Squibb et al., 1990). Early forage exposure may thus enable rapid adjustment to processing novel fibrous feed, such as when forage or TMR is provided at weaning; future work may evaluate whether this could also mitigate neophobia, typically seen when novel feed is presented (Costa et al., 2014). 


\section{Abnormal Repetitive Behaviors}

Calves with access to hay performed fewer ARBs, such as NNOM, in agreement with other studies (Webb et al., 2013; Horvath and Miller-Cushon, 2017, 2019a). Others have suggested that this effect could be a byproduct of increased environmental complexity (e.g., Zhang et al., 2021), reduced hunger (e.g., Margerison et al., 2003), or calves having an outlet for their sucking motivation (e.g., Phillips, 2004). However, calves in both treatments were equally limited in access to milk and sucking time, and both had the ability to consume ad libitum solid feed. This suggests that forage provides certain features, including increased rumination compared with calves fed only grain, are important in reducing NNOM. Commonly studied abnormal behaviors in calves may thus stem in part from an unfulfilled motivation to ruminate and process solid feed, rather than just a need to perform sucking behavior.

Calves have been noted to increase NNOM as they age (Bokkers and Koene, 2001; Horvath and MillerCushon, 2017), especially around weaning (Horvath and Miller-Cushon, 2019a). However, some have also

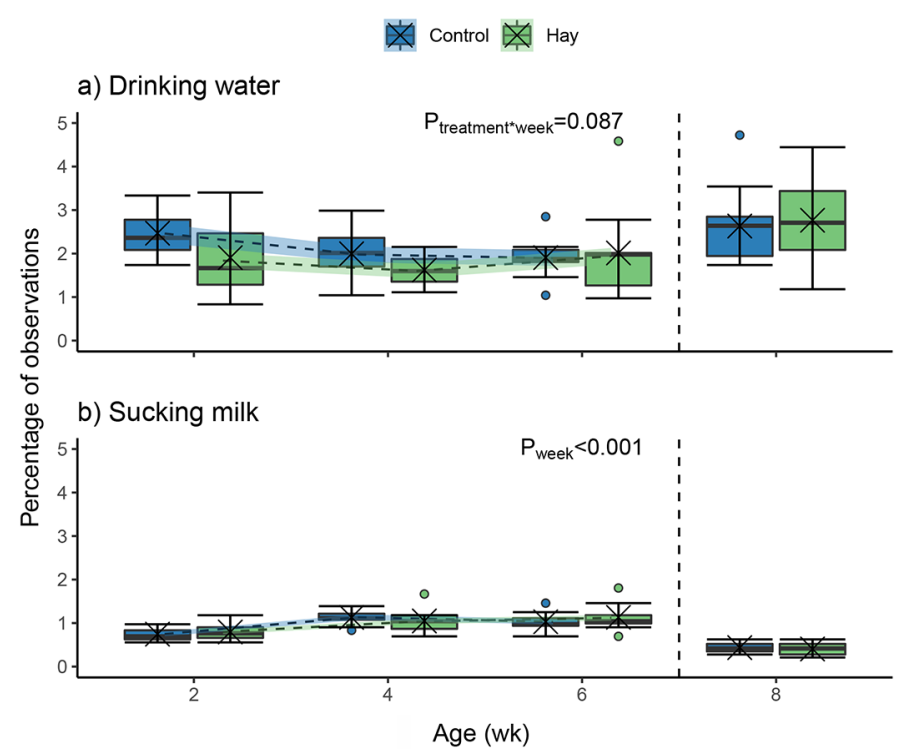

Figure 4. Mean percentage of intervals across $24 \mathrm{~h}$ engaged in drinking water and sucking liquid of calves fed a control diet of starter grain and milk replacer from birth (control) or a control diet with additional mountain grass hay from birth (hay). There was TMR available for all calves at the start of step-down weaning (50-60 $\pm 1 \mathrm{~d})$, as indicated by the dashed line. Data were collected via 1-0 live sampling at 1-min intervals for a continuous $24 \mathrm{~h}$ in wk 2, 4, 6, and 8 and are summarized by treatment and week. Boxplots represent the median (black line within box) and first and third quartiles (25 and $75 \%$ of data). Whiskers extend to the lowest and highest values that are not outliers (values that are $1.5 \times$ the interquartile range); outliers (o) and means $(\mathrm{x})$ are also presented. Model predicted estimates are represented by dotted lines (means) and shaded ribbons (SE). $P$-values $<0.1$ are reported for week (preweaning only), treatment, or interactive effects. suggested that this behavior will stabilize or even decrease as solid-feed intake increases (Margerison et al., 2003; Babu et al., 2004), which is consistent with our results. This may further highlight the direct role of chewing and ruminating in reducing NNOM. It is also possible that NNOM in both treatments was higher than in other studies due to our limit-fed milk, as well as individual housing, which is noted to increase performance of NNOM compared with group housing (Hepola et al., 2006). Most calves tongue rolled at some point during the 8-wk experimental period; however, tongue rolling was still rare in this system, in agreement with other research on calves (occurring for $0.03-0.2 \%$ of observations, Seo et al., 1998; Veissier et al., 2013; too rare to count, Hepola et al., 2006). However, individual calves tongue rolled for up to $2.9 \%$ of observations, which is similar to reports in older milk-fed veal calves (2.1\% of observations; Webb et al., 2015). These calves did not consistently tongue roll in all subsequent observations; along with evidence that tongue rolling commonly begins after weaning (Seo et al., 1998), this may suggest this behavior is still relatively flexible during the preweaning period.

\section{To Be (Normal) or Not to Be: Complexities of Interpreting Oral Behavior}

Hay access reduced tongue flicks and grooming, suggesting they may not be exclusively "normal" or "abnormal" behaviors. Abnormal behavior may be behavioral patterns never seen in a normal context, but they may also be normal behaviors performed out of context (e.g., displacement behaviors) or normal behaviors directed toward inappropriate stimuli (redirected behaviors) performed when animals are experiencing a motivational conflict (e.g., Manning and Dawkins, 2012). Tongue flicks may represent normal hygienic behavior, as animals commonly lick their noses to clear them of mucus, water, or feed, often after feeding events (Meltzer and Githens, 1919). However, their repetitive nature, performance throughout the day (Figure 3), and reduction in response to hay provision (Figure 2) could suggest that tongue flicks may also be related to a frustrated feeding motivation, rather than being exclusively stimulus-elicited. These flicks may also serve as a precursor for tongue rolling, which is commonly considered an abnormal stereotypic behavior (considered a subcategory of ARBs; e.g., Garner, 2005), given their similar motion patterns (Supplemental Videos 11 and 12; https://doi.org/10 .5281 /zenodo.5553444) that reflect natural movements cattle use to rip grass on pasture (Sambraus, 1985; Seo et al., 1998). Self-grooming can similarly be considered normal, as it is used to remove foreign matter from the 
hair and is more common when calves are housed on fine bedding particulates such as sand compared with coarse bedding such as straw (Panivivat et al., 2004). However, grooming was also performed throughout the day (Figure 3) and reduced by hay provision (Figure 2 ). It is often seen as a displacement behavior during motivational conflict, particularly when higher priority behaviors are thwarted. In addition, some authors suggest that intensively managed calves may groom themselves to replicate the contact and stimulation they would naturally receive from maternal grooming (e.g., Zobel et al., 2017; Horvath and Miller-Cushon, 2019b). Being licked may provide comfort or induce a calming effect (Galindo and Broom, 2002; Laister et al., 2011) and has been suggested to be a self-soothing behavior in barren or stressful environments (Kerr and Wood-Gush, 1987; as reviewed by Boissy et al., 2007). Reduced grooming in response to hay provision could thus indicate that hay provides a more stimulating environment that allows calves to perform preferred feeding behaviors; indeed, a similar reduction is found when calves are fed milk via nipples instead of bottles (Pempek et al., 2013). It is also possible that more grooming by control calves may reflect redirected foraging behavior. Licking hair fibers may provide similar oral sensations as manipulating grass or hay, so calves without access to forage may redirect their motivation to chew and ruminate to self-licking instead. Grooming has been positively correlated with tongue rolling in heifers (Seo et al., 1998) and being groomed can elicit tongue movements (Simonsen, 1994), further suggesting that its performance may be linked to the same motivation underlying abnormal tongue motions. Although grooming is commonly suggested to indicate positive welfare in cattle (e.g., Horvath and Miller-Cushon, 2019b), our results suggest that self-licking may have a more complicated interpretation, possibly reflecting a motivational conflict due to inadequate species-specific feeding opportunities.

Rumination, another seemingly normal oral behavior, conversely appears to show abnormality when hay is withheld. Rumination has been reported to start at 3 to 6 wk of age (Margerison et al., 2003) for 8 to $12 \%$ of time in calves fed only grain and milk (Hodgson, 1971; Porter et al., 2007; Liu et al., 2020), but control calves consistently spent $16 \%$ of observations ruminating as early as $2 \mathrm{wk}$ of age. This may suggest that calves prevented from consuming fibrous feed may be performing sham or pseudorumination. Sham or vacuum behaviors are reported in other species when highly motivated behaviors are thwarted (sham chewing in sows; reviewed in Lawrence and Terlouw, 1993; wind-sucking in horses, McGreevy et al., 1995; vacuum dustbathing in poultry, Petherick et al., 1995). Calves in more intensive set- tings have also been reported to ruminate for longer than calves in extensive settings, even when time spent eating was the same (Kerr and Wood-Gush, 1987), suggesting calves may also practice these motions as a way of increasing stimulation in barren environments. Once TMR was introduced at weaning, control calves began ruminating at a level similar to hay. This could suggest that the rapid increase in forage consumption once TMR was provided, and the resultant rumination, may reflect rebound behavior (reviewed in Dawkins, 1988). Rebound behavior can occur after periods of deprivation of important behaviors (e.g., play in calves, reviewed in Held and Špinka, 2011; dustbathing in chickens, Vestergaard, 1982). Indeed, cattle seem motivated to ruminate and will prioritize performance over eating after periods of restricted jaw movement (Welch, 1982). Calves also select diets that allow for more chewing and rumination (Webb et al., 2014) when given a choice. Although sham rumination has never been described for dairy calves before, it has been reported in other settings that restrict rumination, including in cattle fed ground hay diets (Balch, 1952), veal calves fed milk (Sambraus, 1980; Andrighetto et al., 1999), and sheep fed concentrate (Gordon, 1958).

Dairy calves may also respond to limited feeding opportunities by increasing water consumption. Although hay provision did not affect water intake or time spent drinking, the average preweaning intake $(2.8 \mathrm{~L} / \mathrm{d})$ was higher than other reports. Calves may drink 0.3 to $4.7 \mathrm{~L} / \mathrm{d}$ during the preweaning period (as reviewed by Jensen and Vestergaard, 2021), but our findings were higher than $95 \%$ of these studies (average intake $=1.4$ $\mathrm{L} / \mathrm{d}$ ). Our high intake could reflect environmental differences among studies. Cattle may increase consumption of cool water on warm days (Wilks et al., 1990) and reduce water intake if it becomes contaminated (Schütz et al., 2019), suggesting our provision of fresh, clean water $3 \times / d$ during summer could have stimulated more drinking behavior. Water intake is also proportional to DMI (4:1 free water intake to DMI, as reviewed by Jensen and Vestergaard, 2021), and calves in our study may have consumed more water than others, particularly as they aged, in response to their high grain and hay intake. However, this high intake could also be connected to feelings of hunger and an unmet sucking need. Milk provides both water and satiety for calves, and free choice water intake is low when calves are fed ad libitum milk (as reviewed by Jensen and Vestergaard, 2021). In fact, combining water and milk intake throughout the preweaning period leads to an overall liquid intake (5.5 to $11 \mathrm{~L} / \mathrm{d}$ across wk 0-6) that closely matches ad libitum milk intake in calves $(5.5-10.5 \mathrm{~L} / \mathrm{d}$ across wk 0-5, Jasper and Weary, 2002). Water intake then increases at weaning at a level proportional to 
the amount of milk that is reduced (2-fold increase in water intake when calves are limit-fed; e.g., this study, Kertz et al., 1984; Quigley et al., 2006; 11-fold increase when calves are fed ad libitum, Hepola et al., 2008). We also found that 1 calf frequently drank 10 to $20 \mathrm{~L}$ in a single day. Such extremes could reflect polydipsia, or excessive water drinking, which has not previously been reported in dairy calves, to our knowledge. Polydipsia can result from nutrient deficiencies (e.g., salt in cows, Whitlock et al., 1975), but may also stem from frustrated feeding opportunities (e.g., gerbils, Roper, 1978; broiler breeders, Savory et al., 1992; sows, Robert et al., 1993) or exploration (rabbits, Potter and Borkowski, 1998). Water consumption likely reflects an understudied concern about restricting natural feeding opportunities in calves.

\section{More to the Story}

Previous research has focused on explaining prevalence of oral abnormal behaviors through the lens of limited milk provision, affecting both hunger and ability to perform sucking behavior (e.g., Sambraus, 1980; Veissier et al., 2002; Margerison et al., 2003). Our results, however, suggest that there is more to this story. Time spent processing solid feed appears to influence most oral behaviors that calves perform. In our system, calves in both treatments were equally limited in ability to suck milk (Figure 4), suggesting that the main driver of these differences was the time spent chewing and ruminating on forage. In addition, the breadth of behaviors identified in this study suggest that focusing on limited expressions of "abnormal" oral behaviors, commonly cross-sucking in group-housed calves or nonnutritive oral manipulation, does not capture the full story. Some seemingly normal behaviors, such as those that can maintain hygiene (grooming, tongue flicks) or metabolic needs (drinking water, ruminating), may also indicate motivational conflict due to the inability to eat forage. These behaviors may thus reflect novel sources of concern for dairy calf welfare and highlight that the categories of "normal" and "abnormal" behavior may not be as distinct as previously thought. We encourage future research to take a more comprehensive view in scoring these oral behaviors to better understand calf welfare.

\section{CONCLUSIONS}

Contrary to previous reports, abnormal oral behaviors in dairy calves were connected to inability to perform species-specific feeding behavior at large, including chewing and ruminating, rather than solely reflecting thwarted sucking behavior. Hay provision stimulated these chewing behaviors and reduced time engaged in abnormal oral behaviors compared with calves raised with only access to grain, milk replacer, and water. In addition, calf behavior appeared to include more abnormalities than previously identified, with sham rumination, polydipsia, grooming, and tongue flicking possibly reflecting displacement or redirected behaviors. Observing across 24 -h periods and considering all oral behaviors is important to obtain a more comprehensive understanding of calf welfare.

\section{ACKNOWLEDGMENTS}

We thank University of California, Davis Dairy Facility manager Doug Gisi, assistant manager Maria Patino, and the dairy interns for animal care and support. We are grateful to those who assisted with data collection as follows: Sarah Adcock, Montserrat Armero, Rachael Coon, Izabella Czaja, Alycia Drwencke, Stacy Garcia, Rachel Hirota, Amanda Inouye, Peyton Li, Bailey McCarthy, Scott Mill, Mario Rodriguez, and Bret Tobar, all affiliated with UC Davis at the time of the experiment. Special thanks to Allison Pullin (UC Davis) and Christina Rufener (Center for Proper Housing of Ruminants and Pigs, Federal Food Safety and Veterinary Office FSVO, Ettenhausen, $\mathrm{CH}$ ) for inspiration about figures. We gratefully acknowledge the infrastructure support of the Department of Animal Science, College of Agricultural and Environmental Sciences, and the UC Davis California Agricultural Experiment Station. The authors have not stated any conflicts of interest.

\section{REFERENCES}

Andrighetto, I., F. Gottardo, D. Andreoli, and G. Cozzi. 1999. Effect of type of housing on veal calf growth performance, behaviour and meat quality. Livest. Prod. Sci. 57:137-145. https://doi.org/ 10.1016/S0301-6226(98)00170-5.

AOAC International. 2000. Official Methods of Analysis, Vol. 1. 17th ed. AOAC Int.

Appleby, M. C., D. M. Weary, and B. Chua. 2001. Performance and feeding behaviour of calves on ad libitum milk from artificial teats. Appl. Anim. Behav. Sci. 74:191-201. https://doi.org/10.1016/ S0168-1591(01)00171-X.

Arnold, G. W., and R. A. Maller. 1977. Effects of nutritional experience in early and adult life on the performance and dietary habits of sheep. Appl. Anim. Ethol. 3:5-26. https://doi.org/10.1016/0304 -3762(77)90067-0.

Babu, L. K., H. N. Pandey, and A. Sahoo. 2004. Effect of individual versus group rearing on ethological and physiological responses of crossbred calves. Appl. Anim. Behav. Sci. 87:177-191. https://doi .org/10.1016/j.applanim.2004.01.006.

Balch, C. C. 1952. Factors affecting the utilization of food by dairy cows. 6. The rate of contraction of the reticulum. Br. J. Nutr. 6:366-375. https://doi.org/10.1079/BJN19520039.

Bates, D., M. Mächler, B. Bolker, and S. Walker. 2015. Fitting linear mixed-effects models using lme4. J. Stat. Softw. 67:1-48. https:// doi.org/10.18637/jss.v067.i01. 
Beauchemin, K. A. 2018. Invited review: Current perspectives on eating and rumination activity in dairy cows. J. Dairy Sci. 101:47624784. https://doi.org/10.3168/jds.2017-13706.

Boissy, A., G. Manteuffel, M. B. Jensen, R. O. Moe, B. Spruijt, L. J. Keeling, C. Winckler, B. Forkman, I. Dimitrov, J. Langbein, M. Bakken, I. Veissier, and A. Aubert. 2007. Assessment of positive emotions in animals to improve their welfare. Physiol. Behav. 92:375-397. https://doi.org/10.1016/j.physbeh.2007.02.003.

Bokkers, E. A., and P. Koene. 2001. Activity, oral behaviour and slaughter data as welfare indicators in veal calves: A comparison of three housing systems. Appl. Anim. Behav. Sci. 75:1-15. https: //doi.org/10.1016/S0168-1591(01)00175-7.

Brooks, M. E., K. Kristensen, K. J. van Benthem, A. Magnusson, C. W. Berg, A. Nielsen, H. J. Skaug, M. Mächler, and B. M. Bolker. 2017. glmmTMB balances speed and flexibility among packages for zero-inflated generalized linear mixed modeling. R J. 9:378400. https://doi.org/10.32614/RJ-2017-066.

Castells, L., A. Bach, G. Araujo, C. Montoro, and M. Terré. 2012. Effect of different forage sources on performance and feeding behavior of Holstein calves. J. Dairy Sci. 95:286-293. https://doi.org/10 $.3168 / \mathrm{jds} .2011-4405$.

Castells, L., A. Bach, A. Aris, and M. Terré. 2013. Effects of forage provision to young calves on rumen fermentation and development of the gastrointestinal tract. J. Dairy Sci. 96:5226-5236. https:// doi.org/10.3168/jds.2012-6419.

Chapman, C. E., P. S. Erickson, J. D. Quigley, T. M. Hill, H. G. Bateman II, F. X. Suarez-Mena, and R. L. Schlotterbeck. 2016. Effect of milk replacer program on calf performance and digestion of nutrients with age of the dairy calf. J. Dairy Sci. 99:2740-2747. https://doi.org/10.3168/jds.2015-10372.

Costa, J. H. C., R. R. Daros, M. A. G. von Keyserlingk, and D. M. Weary. 2014. Complex social housing reduces food neophobia in dairy calves. J. Dairy Sci. 97:7804-7810. https://doi.org/10.3168/ jds.2014-8392.

Dawkins, M. S. 1988. Behavioural deprivation: A central problem in animal welfare. Appl. Anim. Behav. Sci. 20:209-225. https://doi .org/10.1016/0168-1591(88)90047-0.

de Passillé, A. M. B. 2001. Sucking motivation and related problems in calves. Appl. Anim. Behav. Sci. 72:175-187. https://doi.org/10 .1016/S0168-1591(01)00108-3.

Dennis, T. S., F. X. Suarez-Mena, T. M. Hill, J. D. Quigley, R. L. Schlotterbeck, and L. Hulbert. 2018. Effect of milk replacer feeding rate, age at weaning, and method of reducing milk replacer to weaning on digestion, performance, rumination, and activity in dairy calves to 4 months of age. J. Dairy Sci. 101:268-278. https:/ /doi.org/10.3168/jds.2017-13692.

European Council. 2008. Council Directive 2008/119/EC of 18 December 2008. Laying down minimum standards for the protection of calves. Off. J. Eur. Union 10:7-13.

Fox, J., and S. Weisberg. 2019. An R Companion to Applied Regression. 3rd ed. SAGE.

Galindo, F., and D. M. Broom. 2002. The effects of lameness on social and individual behavior of dairy cows. J. Appl. Anim. Welf. Sci. 5:193-201. https://doi.org/10.1207/S15327604JAWS0503_03.

Gamer, M., J. Lemon, I. Fellows, and P. Singh. 2019. irr: Various coefficients of interrater reliability and agreement. $\mathrm{R}$ package version 0.84.1. Accessed Apr. 28, 2021. https://CRAN.R-project.org/ package $=$ irr .

Garner, J. P. 2005. Perseveration and stereotypy-Systems-level insights from clinical psychology. Pages 121-152 in Stereotypic Animal Behaviour: Fundamentals and Applications to Welfare. G. J. Mason, J. Rushen, eds. CAB International.

Gordon, J. G. 1958. The act of rumination. J. Agric. Sci. 50:34-42. https://doi.org/10.1017/S0021859600029841.

Haley, D. B., J. Rushen, I. J. H. Duncan, T. M. Widowski, and A. M. B. de Passillé. 1998. Effects of resistance to milk flow and the provision of hay on nonnutritive sucking by dairy calves. J. Dairy Sci. 81:2165-2172. https://doi.org/10.3168/jds.S0022-0302(98)75794 $-7$.

Hammell, K. L., J. H. M. Metz, and P. Mekking. 1988. Sucking behaviour of dairy calves fed milk ad libitum by bucket or teat.
Appl. Anim. Behav. Sci. 20:275-285. https://doi.org/10.1016/0168 -1591(88)90052-4.

Hartig, F. 2021. DHARMa: Residual diagnostics for hierarchical (multi-level/mixed) regression models. $\mathrm{R}$ package version 0.4.1. Accessed Apr. 28, 2021. https://CRAN.R-project.org/package= DHARMa

Heinrichs, A. J., D. W. Rogers, and J. B. Cooper. 1992. Predicting body weight and wither height in Holstein heifers using body measurements. J. Dairy Sci. 75:3576-3581. https://doi.org/10.3168/ jds.S0022-0302(92)78134-X.

Held, S. D. E., and M. Špinka. 2011. Animal play and animal welfare. Anim. Behav. 81:891-899. https://doi.org/10.1016/j.anbehav.2011 .01.007.

Hepola, H., L. Hänninen, P. Pursiainen, V.-M. Tuure, L. Syrjälä-Qvist, M. Pyykkönen, and H. Saloniemi. 2006. Feed intake and oral behaviour of dairy calves housed individually or in groups in warm or cold buildings. Livest. Sci. 105:94-104. https://doi.org/10.1016/ j.livsci.2006.04.033.

Hepola, H. P., L. T. Hänninen, S. M. Raussi, P. A. Pursiainen, A.-M. Aarnikoivu, and H. S. Saloniemi. 2008. Effects of providing water from a bucket or a nipple on the performance and behavior of calves fed ad libitum volumes of acidified milk replacer. J. Dairy Sci. 91:1486-1496. https://doi.org/10.3168/jds.2007-0500.

Hill, T. M., H. G. Bateman II, J. M. Aldrich, and R. L. Schlotterbeck. 2008. Effects of the amount of chopped hay or cottonseed hulls in a textured calf starter on young calf performance. J. Dairy Sci. 91:2684-2693. https://doi.org/10.3168/jds.2007-0935.

Hodgson, J. 1971. The development of solid food intake in calves. 2. Studies on the volume of rumen fluid, determined by an indirect method. Anim. Sci. 13:25-36. https://doi.org/10.1017/ S0003356100029408.

Horvath, K. C., A. N. Allen, and E. K. Miller-Cushon. 2020. Effects of access to stationary brushes and chopped hay on behavior and performance of individually housed dairy calves. J. Dairy Sci. 103:8421-8432. https://doi.org/10.3168/jds.2019-18042.

Horvath, K. C., and E. K. Miller-Cushon. 2017. The effect of milkfeeding method and hay provision on the development of feeding behavior and non-nutritive oral behavior of dairy calves. J. Dairy Sci. 100:3949-3957. https://doi.org/10.3168/jds.2016-12223.

Horvath, K. C., and E. K. Miller-Cushon. 2019a. Evaluating effects of providing hay on behavioral development and performance of group-housed dairy calves. J. Dairy Sci. 102:10411-10422. https:/ /doi.org/10.3168/jds.2019-16533.

Horvath, K. C., and E. K. Miller-Cushon. 2019b. Characterizing grooming behavior patterns and the influence of brush access on the behavior of group-housed dairy calves. J. Dairy Sci. 102:34213430. https://doi.org/10.3168/jds.2018-15460.

Jasper, J., and D. M. Weary. 2002. Effects of ad libitum milk intake on dairy calves. J. Dairy Sci. 85:3054-3058. https://doi.org/10.3168/ jds.S0022-0302(02)74391-9.

Jensen, M. B., and M. Vestergaard. 2021. Invited review: Freedom from thirst - Do dairy cows and calves have sufficient access to drinking water? J. Dairy Sci. 104:11368-11385. https://doi.org/10 .3168/jds.2021-20487.

Kassambara, A. 2020. ggpubr: 'ggplot2' based publication ready plots. $\mathrm{R}$ package version 0.4.0. Accessed Apr. 28, 2021. https://CRAN.R -project.org $/$ package $=$ ggpubr.

Kerr, S. G. C., and D. G. M. Wood-Gush. 1987. A comparison of the early behaviour of intensively and extensively reared calves. Anim. Sci. 45:181-190. https://doi.org/10.1017/S0003356100018778.

Kertz, A. F., L. F. Reutzel, and J. H. Mahoney. 1984. Ad libitum water intake by neonatal calves and its relationship to calf starter intake, weight gain, feces score, and season. J. Dairy Sci. 67:29642969. https://doi.org/10.3168/jds.S0022-0302(84)81660-4.

Khan, M. A., D. M. Weary, and M. A. G. von Keyserlingk. 2011. Hay intake improves performance and rumen development of calves fed higher quantities of milk. J. Dairy Sci. 94:3547-3553. https://doi .org/10.3168/jds.2010-3871.

Kooijman, J., H. K. Wierenga, and P. Wiepkema. 1991. Development of abnormal oral behaviour in group-housed veal calves: Effects of 
roughage supply. Pages 54-58 in Proc. of International Symposium on Veal Calf Production. EAAP.

Laister, S., B. Stockinger, A. M. Regner, K. Zenger, U. Knierim, and C. Winckler. 2011. Social licking in dairy cattle-Effects on heart rate in performers and receivers. Appl. Anim. Behav. Sci. 130:8190. https://doi.org/10.1016/j.applanim.2010.12.003.

Latham, N., and G. Mason. 2010. Frustration and perseveration in stereotypic captive animals: Is a taste of enrichment worse than none at all? Behav. Brain Res. 211:96-104. https://doi.org/10.1016/j .bbr.2010.03.018.

Lawrence, A. B., and E. M. Terlouw. 1993. A review of behavioral factors involved in the development and continued performance of stereotypic behaviors in pigs. J. Anim. Sci. 71:2815-2825. https:// doi.org/10.2527/1993.71102815x.

Lidfors, L. M. 1993. Cross-sucking in group-housed dairy calves before and after weaning off milk. Appl. Anim. Behav. Sci. 38:15-24. https://doi.org/10.1016/0168-1591(93)90038-Q.

Liu, S., J. Ma, J. Li, G. M. Alugongo, Z. Wu, Y. Wang, S. Li, and Z. Cao. 2020. Effects of pair versus individual housing on performance, health, and behavior of dairy calves. Animals (Basel) 10:50. https://doi.org/10.3390/ani10010050

Manning, A., and M. S. Dawkins. 2012. An Introduction to Animal Behavior. 6th ed. Cambridge University Press.

Margerison, J. K., T. R. Preston, N. Berry, and C. J. C. Phillips. 2003. Cross-sucking and other oral behaviours in calves, and their relation to cow suckling and food provision. Appl. Anim. Behav. Sci. 80:277-286. https://doi.org/10.1016/S0168-1591(02)00231-9.

Mason, G., and N. Latham. 2004. Can't stop, won't stop: Is stereotypy a reliable welfare indicator. Anim. Welf. 13:57-69.

McGreevy, P. D., J. D. Richardson, C. J. Nicol, and J. G. Lane. 1995. Radiographic and endoscopic study of horses performing an oral based stereotypy. Equine Vet. J. 27:92-95. https://doi.org/10 .1111/j.2042-3306.1995.tb03042.x.

Meltzer, S. J., and T. S. Githens. 1919. The nose-licking reflex and its inhibition. Am. J. Physiol. 50:377-382. https://doi.org/10.1152/ ajplegacy.1919.50.3.377.

Miller-Cushon, E. K., C. Montoro, A. Bach, and T. J. DeVries. 2013 Effect of early exposure to mixed rations differing in forage particle size on feed sorting of dairy calves. J. Dairy Sci. 96:3257-3264. https://doi.org/10.3168/jds.2012-6415.

Montoro, C., E. K. Miller-Cushon, T. J. DeVries, and A. Bach. 2013. Effect of physical form of forage on performance, feeding behavior, and digestibility of Holstein calves. J. Dairy Sci. 96:1117-1124. https://doi.org/10.3168/jds.2012-5731.

Newton-Fisher, N. E. 2012. Animal Behaviour Pro: 1.4.4. Accessed Jul 22, 2018. https://itunes.apple.com/gb/app/animal-behaviour -pro/id579588319? $\mathrm{mt}=8$.

Nolte, D. L., F. D. Provenza, and D. F. Balph. 1990. The establishment and persistence of food preferences in lambs exposed to selected foods. J. Anim. Sci. 68:998-1002. https://doi.org/10.2527/ 1990.684998x

Panivivat, R., E. B. Kegley, J. A. Pennington, D. W. Kellogg, and S. L. Krumpelman. 2004. Growth performance and health of dairy calves bedded with different types of materials. J. Dairy Sci. 87:3736-3745. https://doi.org/10.3168/jds.S0022-0302(04)73512 -2 .

Pempek, J. A., M. L. Eastridge, N. A. Botheras, C. C. Croney, and W. S. Bowen Yoho. 2013. Effects of alternative housing and feeding systems on the behavior and performance of dairy heifer calves. Prof. Anim. Sci. 29:278-287. https://doi.org/10.15232/S1080 -7446(15)30234-5.

Petherick, J. C., E. Seawright, D. Waddington, I. J. H. Duncan, and L. B. Murphy. 1995. The role of perception in the causation of dustbathing behaviour in domestic fowl. Anim. Behav. 49:1521-1530. https://doi.org/10.1016/0003-3472(95)90073-X.

Phillips, C. J. C. 2004. The effects of forage provision and group size on the behavior of calves. J. Dairy Sci. 87:1380-1388. https://doi .org/10.3168/jds.S0022-0302(04)73287-7.

Porter, J. C., R. G. Warner, and A. F. Kertz. 2007. Effect of fiber level and physical form of starter on growth and development of dairy calves fed no forage. Prof. Anim. Sci. 23:395-400. https://doi.org/ 10.15232/S1080-7446(15)30994-3.

Potter, M. P., and G. L. Borkowski. 1998. Apparent psychogenic polydipsia and secondary polyuria in laboratory-housed New Zealand white rabbits. Contemp. Top. Lab. Anim. Sci. 37:87-89.

Quigley, J. D., T. A. Wolfe, and T. H. Elsasser. 2006. Effects of additional milk replacer feeding on calf health, growth, and selected blood metabolites in calves. J. Dairy Sci. 89:207-216. https://doi .org/10.3168/jds.S0022-0302(06)72085-9.

Redbo, I., M. Emanuelson, K. Lundberg, and N. Oredsson. 1996. Feeding level and oral stereotypies in dairy cows. Anim. Sci. 62:199206. https://doi.org/10.1017/S1357729800014491.

Redbo, I., and A. Nordblad. 1997. Stereotypies in heifers are affected by feeding regime. Appl. Anim. Behav. Sci. 53:193-202. https:// doi.org/10.1016/S0168-1591(96)01145-8

Robert, S., J. J. Matte, C. Farmer, C. L. Girard, and G. P. Martineau. 1993. High-fibre diets for sows: Effects on stereotypies and adjunctive drinking. Appl. Anim. Behav. Sci. 37:297-309. https:// doi.org/10.1016/0168-1591(93)90119-A.

Roper, T. J. 1978. The effect of food deprivation on drinking and running in Mongolian gerbils. Anim. Behav. 26:1264-1272. https://doi .org/10.1016/0003-3472(78)90117-3.

Rosenberger, K., J. H. C. Costa, H. W. Neave, M. A. G. von Keyserlingk, and D. M. Weary. 2017. The effect of milk allowance on behavior and weight gains in dairy calves. J. Dairy Sci. 100:504-512. https://doi.org/10.3168/jds.2016-11195.

Rushen, J., and A. M. B. de Passillé. 1995. The motivation of non-nutritive sucking in calves, Bos taurus. Anim. Behav. 49:1503-1510. https://doi.org/10.1016/0003-3472(95)90071-3.

Salter, R. S., K. J. Reuscher, and J. M. C. Van Os. 2021. Milk- and starter-feeding strategies to reduce cross sucking in pair-housed calves in outdoor hutches. J. Dairy Sci. 104:6096-6112. https://doi .org/10.3168/jds.2020-19380.

Sambraus, H. H. 1980. Human considerations in calf rearing. Anim. Regul. Stud. 3:19-22.

Sambraus, H. H. 1985. Mouth-based anomalous syndromes. Pages 391-422 in Ethology of Farm Animals: A Comprehensive Study of the Behavioral Features of the Common Farm Animals. A. F. Fraser, ed. Elsevier.

Savory, C. J., E. Seawright, and A. Watson. 1992. Stereotyped behaviour in broiler breeders in relation to husbandry and opioid receptor blockade. Appl. Anim. Behav. Sci. 32:349-360. https://doi.org/ 10.1016/S0168-1591(05)80027-9.

Schütz, K. E., F. J. Huddart, and N. R. Cox. 2019. Manure contamination of drinking water influences dairy cattle water intake and preference. Appl. Anim. Behav. Sci. 217:16-20. https://doi.org/10 .1016/j.applanim.2019.05.005.

Seo, T., S. Sato, K. Kosaka, N. Sakamoto, K. Tokumoto, and K. Katoh. 1998. Development of tongue-playing in artificially reared calves: effects of offering a dummy-teat, feeding of short cut hay and housing system. Appl. Anim. Behav. Sci. 56:1-12. https://doi .org/10.1016/S0168-1591(97)00078-6.

Simonsen, H. B. 1994. Skin stimulated induction of mouth movements in cattle. Anim. Welf. 3:129-134.

Squibb, R. C., F. D. Provenza, and D. F. Balph. 1990. Effect of age of exposure on consumption of a shrub by sheep. J. Anim. Sci. 68:987-997. https://doi.org/10.2527/1990.684987x.

Swanson, E. W., and J. D. Harris Jr.. 1958. Development of rumination in the young calf. J. Dairy Sci. 41:1768-1776. https://doi.org/ 10.3168/jds.S0022-0302(58)91161-5.

Sweeney, B. C., J. Rushen, D. M. Weary, and A. M. de Passillé. 2010. Duration of weaning, starter intake, and weight gain of dairy calves fed large amounts of milk. J. Dairy Sci. 93:148-152. https:/ /doi.org/10.3168/jds.2009-2427.

Terré, M., L. Castells, M. A. Khan, and A. Bach. 2015. Interaction between the physical form of the starter feed and straw provision on growth performance of Holstein calves. J. Dairy Sci. 98:1101-1109. https://doi.org/10.3168/jds.2014-8151.

Tresoldi, G., K. E. Schütz, and C. B. Tucker. 2016. Assessing heat load in drylot dairy cattle: Refining on-farm sampling methodology. J. Dairy Sci. 99:8970-8980. https://doi.org/10.3168/jds.2016-11353. 
Tucker, C. B., M. B. Jensen, and B. C. Downey. 2022a. Data from: Hay provision affects 24 -h performance of normal and abnormal oral behaviors in dairy calves. Zenodo. https://doi.org/https://doi .org/10.5281/zenodo.5553444.

Tucker, C. B., M. B. Jensen, and B. C. Downey. 2022b. Data from: Hay provision affects 24 -h performance of normal and abnormal oral behaviors in dairy calves. Zenodo. https://doi.org/https://doi .org/10.5281/zenodo.5553442.

USDA. 2016. Dairy 2014: Dairy cattle management practices in the United States. Report No. 1. USDA-APHIS-VS-NAHMS.

Van Soest, P. J., J. B. Robertson, and B. A. Lewis. 1991. Methods for dietary fiber, neutral detergent fiber, and nonstarch polysaccharides in relation to animal nutrition. J. Dairy Sci. 74:3583-3597. https://doi.org/10.3168/jds.S0022-0302(91)78551-2.

Veissier, I., S. Caré, and D. Pomiès. 2013. Suckling, weaning, and the development of oral behaviours in dairy calves. Appl. Anim. Behav. Sci. 147:11-18. https://doi.org/10.1016/j.applanim.2013.05 .002 .

Veissier, I., A. M. B. de Passillé, G. Després, J. Rushen, I. Charpentier, A. R. Ramirez de la Fe, and P. Pradel. 2002. Does nutritive and non-nutritive sucking reduce other oral behaviors and stimulate rest in calves? J. Anim. Sci. 80:2574-2587. https://doi.org/10 $.1093 /$ ansci/80.10.2574.

Vestergaard, K. 1982. Dust-bathing in the domestic fowl - Diurnal rhythm and dust deprivation. Appl. Anim. Ethol. 8:487-495. https://doi.org/10.1016/0304-3762(82)90061-X.

Wang, S., Q. Y. Diao, F. M. Hu, Y. L. Bi, M. Y. Piao, L. S. Jiang, F. Sun, H. Li, and Y. Tu. 2022. Development of ruminating behavior in Holstein calves between birth and 30 days of age. J. Dairy Sci. 105:572-584. https://doi.org/10.3168/jds.2021-20405.

Webb, L. E., E. A. M. Bokkers, L. F. M. Heutinck, B. Engel, W. G. Buist, T. B. Rodenburg, N. Stockhofe-Zurwieden, and C. G. van Reenen. 2013. Effects of roughage source, amount, and particle size on behavior and gastrointestinal health of veal calves. J. Dairy Sci. 96:7765-7776. https://doi.org/10.3168/jds.2012-6135.
Webb, L. E., B. Engel, H. Berends, C. G. van Reenen, W. J. J. Gerrits, I. J. M. de Boer, and E. A. M. Bokkers. 2014. What do calves choose to eat and how do preferences affect behaviour? Appl. Anim. Behav. Sci. 161:7-19. https://doi.org/10.1016/j.applanim .2014.09.016.

Webb, L. E., C. G. van Reenen, H. Berends, B. Engel, I. J. M. de Boer, W. J. J. Gerrits, and E. A. M. Bokkers. 2015. The role of solid feed amount and composition and of milk replacer supply in veal calf welfare. J. Dairy Sci. 98:5467-5481. https://doi.org/10.3168/ jds.2014-8547.

Welch, J. G. 1982. Rumination, particle size and passage from the rumen. J. Anim. Sci. 54:885-894. https://doi.org/10.2527/jas1982 $.544885 \mathrm{x}$.

Whitlock, R. H., M. J. Kessler, and J. B. Tasker. 1975. Salt (sodium) deficiency in dairy cattle: Polyuria and polydipsia as prominent clinical features. Cornell Vet. 65:512-526.

Wilks, D. L., C. E. Coppock, J. K. Lanham, K. N. Brooks, C. C. Baker, W. L. Bryson, R. G. Elmore, and R. A. Stermer. 1990. Responses of lactating Holstein cows to chilled drinking water in high ambient temperatures. J. Dairy Sci. 73:1091-1099. https:// doi.org/10.3168/jds.S0022-0302(90)78768-1.

Zhang, C., D. T. Juniper, and R. K. Meagher. 2021. Effects of physical enrichment items and social housing on calves' growth, behaviour and response to novelty. Appl. Anim. Behav. Sci. 237:105295. https://doi.org/10.1016/j.applanim.2021.105295.

Zobel, G., H. W. Neave, H. V. Henderson, and J. Webster. 2017. Calves use an automated brush and a hanging rope when pair-housed. Animals (Basel) 7:84. https://doi.org/10.3390/ani7110084.

\section{ORCIDS}

Blair C. Downey () https://orcid.org/0000-0003-3747-0164 Margit B. Jensen ( https://orcid.org/0000-0001-7982-582X Cassandra B. Tucker (i) https://orcid.org/0000-0002-6014-444X 